Acta Crystallographica Section E

Structure Reports

Online

ISSN 1600-5368

\section{Huey-Sheng Shieh and Christer E. Nordman*}

Department of Chemistry, University of Michigan, Ann Arbor, MI 48109, USA

Correspondence e-mail: cnordman@umich.edu

\section{Key indicators}

Single-crystal X-ray study

$T=293 \mathrm{~K}$

Mean $\sigma(\mathrm{C}-\mathrm{C})=0.010 \AA$

$R$ factor $=0.054$

$w R$ factor $=0.102$

Data-to-parameter ratio $=6.2$

For details of how these key indicators were automatically derived from the article, see http://journals.iucr.org/e.

\title{
Cholesterol hemimethanol solvate
}

The structure of cholesterol hemimethanol solvate, $\mathrm{C}_{27} \mathrm{H}_{46} \mathrm{O} \cdot 0.5 \mathrm{CH}_{4} \mathrm{O}$, is of the bilayer type, with a head-to-head tail-to-tail arrangement of cholesterol molecules, forming alternating hydrophilic and hydrophobic layers. The four cholesterol and two methanol molecules in the asymmetric unit are connected into a single hydrogen-bonded chain.

\section{Comment}

The unit cell of cholesterol hemimethanol solvate, (I), has been reported by Klötzer (1936) and a preliminary report by us (Shieh \& Nordman, 1978) gave the unit cell and space group. In this paper, the refined structure is presented.

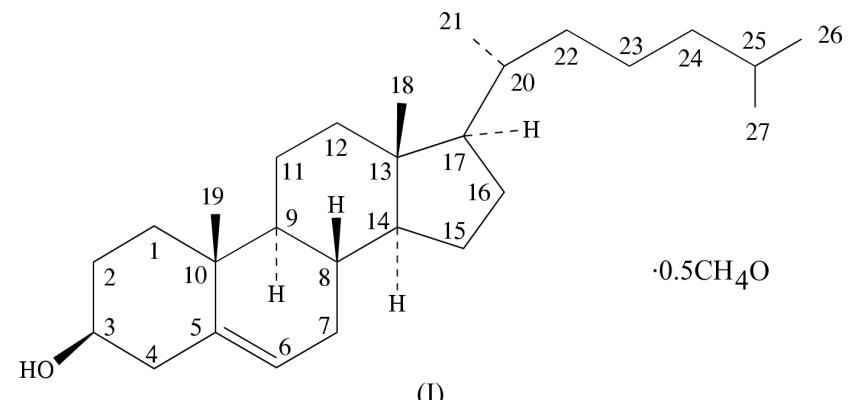

(I)

All reported structures of cholesterol and its solvates have asymmetric units containing multiple cholesterol molecules. Room-temperature cholesterol has eight (Shieh et al., 1981), its high-temperature form 16 (Hsu \& Nordman, 1983; Hsu et al., 2002), cholesterol hydrate eight (Craven, 1979), and monoclinic and triclinic cholesterol hemiethanolate each eight (Shieh et al., 1982). With only four cholesterol molecules in the asymmetric unit, the present sructure is the simplest of the group. Furthermore, cholesterol hemimethanol solvate lacks any obvious pseudosymmetry, as distinct from the aforementioned structures, which exhibit several forms of pseudosymmetry. The hydrogen-bonded chain $\cdots \mathrm{C} 1-\mathrm{C} 2-M 1-\mathrm{C} 3-$ $\mathrm{C} 4-M 2-\mathrm{C} 1 \cdots$ is similar to the cholesterol-ethanol chains found in both forms of cholesterol hemiethanolate. The structure differs from other cholesterol structures in the relative orientation of adjacent molecules; the mean planes of the steroid groups of molecules hydrogen bonded to each other are very nearly parallel, while the planes of laterally adjacent molecules are approximately perpendicular to one another. The cholesterol molecule, in all its crystal forms, shows extreme thermal motion or disorder in the hydrocarbon tails. In the hemimethanolate there is clear disorder in the tails of molecules 2 and 3. 


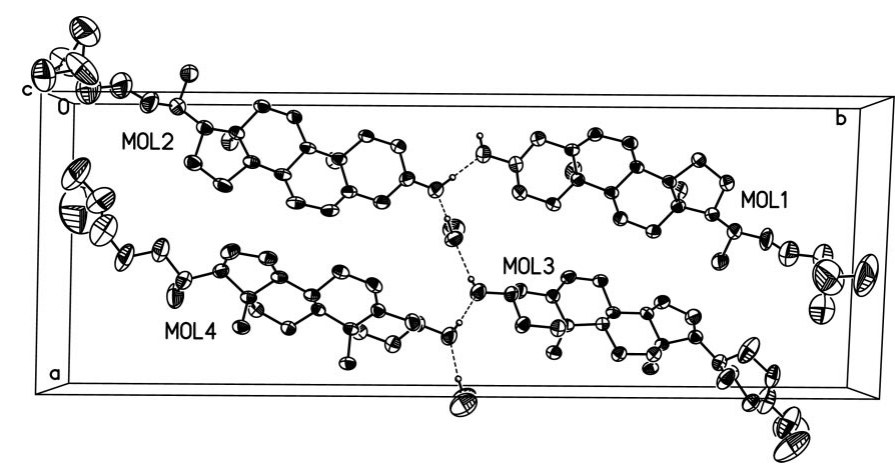

Figure 1

One unit cell of the cholesterol hemimethanol solvate structure showing $25 \%$ probability displacement ellipsoids.

\section{Experimental}

Crystals were grown by slow evaporation of a methanol solution.

\section{Crystal data}

$\mathrm{C}_{27} \mathrm{H}_{46} \mathrm{O} \cdot 0.5 \mathrm{CH}_{4} \mathrm{O}$

$M_{r}=402.66$

Triclinic, $P 1$

$a=12.2735$ (17) ^

$b=34.237$ (7) $\AA$

$c=6.2739(8) \AA$

$\alpha=90.224(14)^{\circ}$

$\beta=93.705(10)^{\circ}$

$\gamma=91.576(14)^{\circ}$

$V=2629.8(7) \AA^{3}$

$$
\begin{aligned}
& Z=4 \\
& D_{x}=1.017 \mathrm{Mg} \mathrm{m}^{-3} \\
& \text { Cu } K \alpha \text { radiation } \\
& \text { Cell parameters from } 15 \\
& \quad \text { reflections } \\
& \theta=24-31^{\circ} \\
& \mu=0.45 \mathrm{~mm}^{-1} \\
& T=293(2) \mathrm{K} \\
& \text { Plate, colourless } \\
& 0.50 \times 0.30 \times 0.10 \mathrm{~mm}
\end{aligned}
$$

\section{Data collection}

Syntex $P \overline{1}$ diffractometer $\omega-2 \theta$ scans

7176 measured reflections 7176 independent reflections

5452 reflections with $I>2 \sigma(I)$

$\theta_{\max }=57.4^{\circ}$

$$
\begin{aligned}
& h=0 \rightarrow 13 \\
& k=-37 \rightarrow 37 \\
& l=-6 \rightarrow 6 \\
& 3 \text { standard reflections } \\
& \quad \text { every } 50 \text { reflections } \\
& \text { intensity decay: } 6 \%
\end{aligned}
$$

\section{Refinement}

Refinement on $F^{2}$ $R\left[F^{2}>2 \sigma\left(F^{2}\right)\right]=0.054$ $w R\left(F^{2}\right)=0.102$

$S=2.09$

6750 reflections

1097 parameters

$\mathrm{H}$ atoms treated by a mixture of independent and constrained refinement

$w=1 /\left[\sigma^{2}\left(F_{o}^{2}\right)+(0.0171 P)^{2}\right]$

where $P=\left(F_{o}^{2}+2 F_{c}^{2}\right) / 3$

$(\Delta / \sigma)_{\max }=0.001$
Modest restraints (DFIX and DELU) were applied to first and second nearest-atom distances in the hydrocarbon tails of the cholesterol molecules. Despite being restrained to nominal values, most carbon-carbon bond distances appear short. This implies a wagging motion of the chain ends, with presumably kidney-shaped atoms modelled as ellipsoids with shortened bonds. The choice of extreme thermal motion or disorder in the tails of the cholesterol molecules presented a difficulty. After refining several models we have chosen to model only the two most obvious cases (C25_2 and C21_3, C22_3, C23_3) as disordered. Given the limited data, no convincing improvement was achieved by modeling additional atoms as disordered. The weight parameters were arrived at by an iterative procedure in which the mean standard uncertainties of the $\mathrm{O}$ - and ordered C-atom coordinates were minimized. This resulted in significantly lower s.u.'s for the atom coordinates, and allowed the $S$ parameters to deviate more from unity.

Data collection: Syntex $P \overline{1}$ Software (Sparks, 1970); cell refinement: Syntex P1 Software; data reduction: SYNOUT (Sparks, 1970); program(s) used to solve structure: Patterson search (Schilling, 1970) and MULTAN (Germain et al., 1971); program(s) used to refine structure: SHELXL97 (Sheldrick, 1997); molecular graphics: SHELXTL (Sheldrick, 1994); software used to prepare material for publication: SHELXL97.

This work was supported by grant GM15259 from the National Institutes of Health.

\section{References}

Craven, B. M. (1979). Acta Cryst. B35, 1123-1128.

Germain, G., Main, P. \& Woolfson, M. M. (1971). Acta Cryst. A27, 368-376. Hsu, L.-Y. \& Nordman, C. E. (1983). Science, 220, 604-606.

Hsu, L.-Y., Kampf, J. \& Nordman, C. E. (2002). Acta Cryst. B58. In the press. Klötzer, F. (1936). Z. Kristallogr. 95, 338-367.

Schilling, J. W. (1970). Crystallographic Computing, edited by F. R. Ahmed, pp. 115-123. Copenhagen: Munksgaard.

Sheldrick, G. M. (1994). SHELXTL. Version 5.10. Bruker AXS Inc., Madison, Wisconsin, USA.

$\Delta \rho_{\max }=0.17 \mathrm{e} \AA^{-3}$

$\Delta \rho_{\min }=-0.15$ e $\AA^{-3}$
Sheldrick, G. M. (1997). SHELXL97. University of Göttingen, Germany. Shieh, H.-S. \& Nordman, C. E. (1978). Am. Crystallogr. Assoc. Ser. 2, 6, 22. Shieh, H.-S., Hoard, L. G. \& Nordman, C. E. (1981). Acta Cryst. B37, 1538 1543.

Shieh, H.-S., Hoard, L. G. \& Nordman, C. E. (1982). Acta Cryst. B38, 24112419.

Sparks, R. A. (1970). Am. Crystallogr. Assoc. Meet. Ottawa, p. 20, Abstract A1. 